\title{
Contents, Vol. 61, 1927
}

\section{Inhaíts - Verzeichnis.}

Ëigenarbeiteli. Seite

Berneaud, G., Menstruation und Tuberkulose des Auges 315 Car, A., Eine neue Artder knötchenförmigen Degeneration

der Hornhaut mit anatomischem Befund, ähnlich der-

jenigen nach Groeunouw 335

Fuchs, A., Über Wucherungen des Hornhautendothels . 1 Heßberg, K., Zur Ermöglichung des

Brillentragens unter

Tage 47

vom Hofe, K., Über Divergenzlähmung 54

Lose, P,. Zur Desinfektion des Lidrandes 348

Maiüard, Über das subaquale Darmbad (Sudabad) und seine

Anwendung in der Augenheilkunde 242

Mylius, K., Erfahrungen mit der Strahlenbehandlung tuber-

kulöser Erkrankungen des vorderen Augenabschnittes 230 zur Neddsn, Die äußere Anwendung

von Jod bei Augen-

krankheiten 247

Pick, L., Augen- und Schleimhauterkrankungen durch Mor-

chelausdünstungen (gewerbliche Massenerkrankung) 325 Preßburger, E., Über vereinzelte

periphere chorioiditische

Herde 143

Procksch, M., Beitrag zum Glaukomgesichtsfeld . . . 344 Rauh, W., Beitrag zur Kenntnis der

Bildung glashäutiger

Membranen auf der Iris

169

Sachs, M., Zur Behandlung der Ablatio retinae .... 177 Safar, K., Zur Pathogenese der

Pyozyaneusinfektion der

Hornhaut 25

Sander, P., Ein Fall von angeborenem Kolobomader Augen-

lider . . 180

Schall, E., Über sogenannte „variköse Nervenfasern” . . 51 Simons, A., Ergebnisse bei

Behandlung von Karzinomen

der Augenlider mittels Thor X-Stäbchen 211

Tschermak, A., Binokularsehen und Sehnervenkreuzung 205 Urbanek, /., Lichtdermatitis und eine Lichterkrankung der

Konjunktiva 66

Wagner-Jauregg, Über tabische Optikusatrophie und deren

Behandlung , 127

Wanecek, 0., Die Wiener Sehschwachenschule und ihre

Methode . 251 
Zimmermann, St., Erfahrungen über Knorpelimplantation

nach Enukleation 63

Aus der Praxis îür die Praxis.

Edeskuty, 0., Lidfixierung bei Staroperationen .... 256Lindemann, K., Bericht über einen Fall von Erblindungdurch Einatmen von Nachschwaden von Dynamit-sprengung im Grubenbetrieb 72

$-\mathrm{IV}-$

Seite

Lose, P., Zur Herstellung provisorischer Prothesen ...

Kurze Bemerkung hierzu von Dr. Quint .... 352

Stiel, Rachenmandel und Auge $\quad 70$

Katarakt-Conjunctivitis (Frage - Antwort) 257

Berichte über die deutsche ophthalmologische Literatur.

Neurologie des Auges (1924-1925). Sehbahn. Von Dr. Peter

Kronfeld in Wien 80

Berichte über die ausländische ophthalmologische Literatur.

Bericht über die italienische Literatur 1924. Von Dr. F. Farina und

Dr. E. Guzmann in Wien 259

Gesellschaf tsberi chte.

Ophthalmolog. Gesellschaft in Wien. Sitzung vom 5. Juli 1926 . 100

Sitzung vom 18. Oktober 1926102 Sitzung vom 8. November 1926184 Sitzung vom 6.

Dezember 1926275 Sitzung vom 13.Dezember 1926278 Sitzung vom 17. Januar 1927 . 388

Verein der Augenärzte von Ost- und Westpreußen.

Sitzung vom 31. Mai 1924 in Königsberg i. Pr. 107 Sitzung vom 6. Juni 1925 in Königsberg i. Pr. Ill Bericht über die XII. Sitzung der Ophthalmologischen Abteilung der Gesellschaft für

Wissenschaít und Leben im Rhein.-Westf.

Industriebezirk am 24. Juli $1926 \quad 114$

Vereinigung mitteldeutscher Augenärzte. Sitzung vom 28. November 1926 in Leipzig 280

Berliner Augenärztliche Gesellschaft. Sitzungen vom 28. Oktober

und 25. November $1926 \quad 295$

Augenärztliche Gesellschaft in Hamburg. Sitzung vom 3. Dezember 1926300

Bericht über die 49. Versammlung des Vereins rheinisch-westfäli-

scher Augenärzte in Essen am 21. November 1926301

Erste Versammlung russischer Augenärzte der UdSSR in Moskau

vom 27. IX. bis i.X. $1926 \quad$ 193, 305

Sektion für Augenheilkunde der Vereinigten Medizinischen Gesellschaft in Kiew (Ukraine).

Sitzungen vom 17. Mai u. 27. Mai 1926 307Bericht über die I. Tagung der Bayerischen

augenärztlichen Vereinigung in München am 20. November 1926353

Südostdeutsche Augenärztevereinigung. 17. Tagung am 11. und

12. Dezember 1926 in Breslau 374

Ungarische Ophthalmologische Gesellschaft Budapest. Sitzung vom

20. Oktober $1926 \quad 390$

Diagnose und Therapie 122, 200, 309, 393

Unïall- und Versicherungskunde 125, 313

Nachtrag zu der Arbeit: „Beiträge zur subjektiven Bestimmung des Astigmatismus” (Bd. 60, H. 6, Dez. 1926) von Prof. Lindner 
in Wien

Buchbesprechungen

204

Einladung zur Zusammenkunît der Deutschen Ophthalmologischen Gesellschaft in Heidelberg in der Pfingstwoche am 9., ÍO. und

11. Juni $1927 \quad 397$

Personalien 204, 314, 398

Tagesnaehrichten 3J4

Druckîehlerberichtigung

S. Sachregister 399

Namenregister $\quad 404$ 